\title{
Ação direta, luta institucional, construção democrática: aprendendo com os movimentos de sem-teto
}

Direct action, institutional struggle, democracy
building: learning from the housing movements

Clara Bois [I]

Lígia Milagres [II]

\begin{abstract}
Resumo
Qual o papel da participação social junto ao Estado na produção das cidades no Brasil contemporâneo? Neste artigo, discutimos as práticas de movimentos sociais urbanos que utilizam a luta institucional como forma de combater a (re)produção da desigualdade urbana. Especificamente, estudamos o caso dos movimentos de sem-teto do Centro de São Paulo e sua relação com o Estado na luta pelo direito à moradia. A prática desses movimentos mostra que a atuação crítica junto ao Estado, ainda que possua limites, é crucial para fazer a agenda de moradia social no Centro avançar. A partir desse caso, identificamos alguns caminhos para a consolidação de pautas de justiça socioespacial por meio da política institucional que podem ser adotados por outras organizações populares.
\end{abstract}

Palavras-chave: participação; cidadania; insurgência; movimentos sociais urbanos; habitação social.

\begin{abstract}
What is the role of public participation in statesanctioned participatory spaces in the production of cities in contemporary Brazil? This paper discusses the practices of urban social movements that use state-sanctioned participatory spaces to fight against the (re)production of urban inequality. Specifically, we study the case of the homeless movements in Downtown São Paulo and their relationship to the state in their struggle for the right to housing. The practices developed by these movements show that critical action towards the state, although limited, has been crucial to further the agenda of social housing in Downtown São Paulo. Based on this case, we identify how other popular organizations can use critical state-sanctioned participation to advance social and spatial justice agendas.
\end{abstract}

Keywords: participation; citizenship; insurgency; urban social movements; social housing. 


\section{Introdução}

A participação social na formulação, gestão e acompanhamento da política urbana brasileira foi uma das principais reivindicações dos atores sociais que defendiam a agenda da reforma urbana durante o processo de redemocratização no Brasil. Ponto fundamental de um projeto político democrático e participativo, o princípio da gestão participativa proposto naquele contexto visava ao compartilhamento do poder decisório do Estado, à expansão da cidadania e ao aprofundamento da democracia no País (Dagnino, 2004). Esse princípio foi ratificado pela Constituição Federal de 1988 (Brasil, 1988) - posteriormente, regulamentado pelo Estatuto das Cidades -, servindo de base para a criação de espaços de gestão compartilhada no âmbito do Estado, como os conselhos de política urbana e de habitação, e os processos de elaboração dos planos diretores participativos.

0 crescimento dos espaços e das práticas de planejamento participativo ao longo dos últimos 30 anos não implicou, todavia, o aprofundamento desse projeto de compartilhamento de poder. Parte da literatura que aborda a atuação de ativismos e movimentos urbanos chama a atenção para a relevância de ações políticas que ocorrem fora dos espaços de participação institucionais e que dão origem a práticas insurgentes de produção e gestão do espaço urbano. Souza (2006; 2012a; 2012b), por exemplo, critica a perspectiva estadocêntrica do campo do planejamento urbano, argumentando que os movimentos urbanos devem ser considerados agentes de planejamento urbano crítico, atuando "junto ao Estado, apesar do Estado e contra o Estado".
Mais precisamente, o autor defende a complementaridade entre o que ele chama de ação direta (conjunto de práticas que não possuem vínculo com instâncias do Estado) e luta institucional (uso de canais, instâncias e recursos do Estado) - estando a segunda subordinada à primeira.

Em consonância com Souza, o presente artigo reflete sobre a luta institucional feita pelos movimentos sociais urbanos num contexto de abandono da agenda da reforma urbana por parte do Estado. Os desmontes do ConseIho Nacional das Cidades e do Ministério das Cidades pelas administrações dos presidentes Michel Temer (Movimento Democrático Brasileiro, MDB) e Jair Messias Bolsonaro (Partido Social Liberal, PSL) apontam para um cenário de destruição da infraestrutura institucional destinada ao desenvolvimento e à implementação da política urbana nacional. Em que pesem os limites da atuação institucional como estratégia de implementação da reforma urbana, ${ }^{1}$ a desarticulação do Ministério e do ConseIho das Cidades é um evidente retrocesso por comprometer a capacidade de criação e implementação de uma política nacional urbana holística e democrática.

Além disso, o sucesso eleitoral de lideranças ultraconservadoras de perfil populista e autoritário, como o próprio presidente Bolsonaro, ${ }^{2}$ dá novo significado aos espaços institucionais de participação social. Na visão dessas lideranças, políticas de participação social são medidas supérfluas que têm como principal objetivo abrir espaços para grupos de interesse contrários à agenda das autoridades eleitas. ${ }^{3}$ Portanto, diante desse contexto de crescimento do autoritarismo explícito, como podemos pensar a apropriação dos espaços de participação social pelos movimentos e 
ativismos urbanos? Qual é a relevância desses espaços para as estratégias de luta desses grupos socioespaciais hoje?

Para discutir essas questões, analisamos o caso dos movimentos de sem-teto do Centro de São Paulo e sua relação com o Estado na luta por moradia social no Centro. Especificamente, exploramos o caso do Hotel Cambridge, uma ocupação organizada por um desses movimentos - o Movimento dos Sem-Teto do Centro (MSTC) - que foi contemplada com recursos do Programa Minha Casa Minha Vida-Entidades (MCMV-Entidades). Os movimentos de sem-teto do Centro mostram que a atuação junto ao Estado é parte importante da sua estratégia. Se, por um lado, a ocupação de propriedades ociosas ou subutilizadas é um tipo de ação direta que confronta o Estado, por outro, a presença constante desses movimentos nos espaços de participação sancionados pelo Estado faz com que a agenda da moradia social no Centro seja pautada na política urbana e habitacional da cidade de São Paulo.

Este artigo busca contribuir para o debate sobre a gestão e o planejamento participativo das cidades, enfatizando a necessidade de se pensar a participação institucionalizada em termos táticos e estratégicos. Procuramos entender a "política do urbano" (Marques, 2017), buscando aliar os estudos desenvolvidos dentro do campo do planejamento urbano às análises do campo da ciência política. Além disso, visamos a continuar o esforço teórico de Klink e Denaldi (2016), no sentido de compreender o papel ambíguo do Estado enquanto ator-chave da produção do espaço. Assim como Dagnino (2004), rejeitamos uma visão homogeneizadora da sociedade civil como "polo de virtudes" ou do Estado como "encarnação do mal" e procuramos contextualizar a luta institucional - sob uma "perspectiva estadocrítica" (Souza, 2006; 2012a; 2012b) -, tendo em vista um projeto político de aprofundamento da democracia no Brasil. Nossa análise indica que a atuação crítica dos movimentos sociais junto ao Estado, ainda que possua limites, é crucial para fazer avançar agendas de justiça socioespacial no País.

Duas razões principais justificam a escolha dos movimentos de sem-teto do Centro paulistano como foco de estudo. Primeiramente, o repertório de ação dessas organizações populares combina ação direta - principalmente, através da ocupação organizada de imóveis vazios no Centro - e luta institucional com o objetivo de influenciar a política pública de habitação da cidade. Em segundo lugar, a longevidade da atuação dos movimentos de sem-teto do Centro paulistano - alguns ativos desde meados dos anos 1990 - confere maior consistência à análise da interação entre movimentos e Estado. Nesse sentido, a relativa alternância política do governo municipal de São Paulo faz com que esses movimentos tenham que lidar com administrações de diferentes espectros ideológicos, o que pode contribuir para o caráter crítico da atuação dessas organizações junto ao Estado.

Para realizar este estudo, foram conduzidas nove entrevistas semiestruturadas com coordenadores do MSTC entre julho e agosto de 2017. Além disso, foram feitas visitas a dez ocupações organizadas pelo movimento no mesmo período, incluindo o Hotel Cambridge. Por fim, o trabalho de campo foi complementado por uma pesquisa bibliográfica acerca dos movimentos de sem-teto do Centro de São Paulo. 
Este artigo está organizado em cinco seções, incluindo esta introdução. Na segunda seção, discutimos a institucionalização da gestão participativa no Brasil através de uma perspectiva estadocrítica, enfatizando os desafios da participação social em face de uma conjuntura sociopolítica que tem favorecido a ascensão de projetos políticos autoritários, como o representado pelo presidente Jair Bolsonaro. A terceira seção apresenta a questão da moradia no Centro e da participação social na política de habitação da cidade de São Paulo, destacando o caso da ocupação do Hotel Cambridge e o processo de luta que garantiu a conversão do imóvel em habitação social. Na seção quatro, discutimos as nuanças da relação entre movimentos e Estado e analisamos o significado atual das arenas de participação social. A seção cinco conclui o artigo, apontando alguns caminhos para a consolidação de pautas de justiça socioespacial por meio da luta institucional.

\section{Participação social e o projeto de construção democrática}

O direito à participação na formulação e gestão da política urbana brasileira está ratificado no Art. 10 da Constituição de 1988 e no Art. 2은 do Estatuto das Cidades. Demanda articulada pelos movimentos sociais que lutavam pela reforma urbana especialmente durante o período de transição democrática, a criação desses marcos institucionais visava ao compartilhamento do poder do Estado com a sociedade, à ampliação dos direitos de cidadania e ao aprofundamento da democracia brasileira após mais de duas décadas de ditadura militar (Dagnino, 2004). Nesse sentido, a reivindicação pelo direito de participar refletia a própria vivência das organizações populares pró-reforma urbana, cujas práticas cotidianas eram orientadas pelos princípios da autonomia e da autogestão de seus espaços de moradia. Para esses atores sociopolíticos, assegurar a participação direta em decisões políticas importantes era uma forma de reivindicar a cidade como espaço de criação e apropriação coletiva (Klink e Denaldi, 2016).

0 estabelecimento desses marcos formais de gestão levou ao surgimento de uma variedade de espaços de participação social como orçamentos participativos, conselhos de políticas públicas, processos de planejamento participativo, dentre outros - cuja simples criação não implicou, necessariamente, o maior compartilhamento do poder do Estado com a sociedade ou o aprofundamento do processo de construção democrática ao longo das últimas três décadas. Se, por um lado, a institucionalização da participação social forneceu um caminho para resistir às iniciativas autoritárias de planejamento e gestão das cidades através da via judicial; por outro, ela não atenuou a desigualdade de poder que existe entre Estado e sociedade ou entre os próprios atores sociais (Fernandes, 2011; Rolnik, 2013; Caldeira e Holston, 2015).

Ao analisar os limites e dilemas da participação no Brasil, Dagnino (2004) argumenta que, após a transição democrática, projetos políticos antagônicos passaram a disputar os discursos em torno do objetivo da participação social, resultando no que a autora chama de "confluência perversa". Para os atores sociais ligados ao projeto democrático, a participação deveria visar à "emergência de uma cultura mais igualitária que confronta[ria] as 
várias dimensões do autoritarismo social da sociedade brasileira" (ibid., p. 144). Já, para os atores vinculados ao projeto neoliberal, a participação social estaria relacionada ao estabelecimento de parcerias na gestão e provisão de direitos essenciais, de forma a transferir as responsabilidades do Estado para a sociedade civil. Para Dagnino, a perversidade dessa confluência em defesa da participação estaria "no fato de que, apontando para direções opostas e até antagônicas, ambos os projetos requerem uma sociedade civil ativa e propositiva" (ibid., p. 142).

Essa divergência de concepção sobre o objetivo da participação social é um dos fatores que contribui para a implementação de processos participativos diluídos, nos quais o debate público - aqui entendido como a exposição de demandas e projetos políticos divergentes ou não - é abafado em favor da produção de consensos que favoreçam os interesses de grupos políticos no comando do Estado. Ademais, o tecnicismo e a falta de efetividade dos processos de planejamento participativo têm influenciado a desmobilização de atores sociais importantes, colocando em xeque a própria legitimidade desses espaços como lugar do poder de fato (Cavalcanti, 2006; Bois, 2013; Trindade, 2014; Klink e Denaldi, 2016).

No entanto, a ascensão eleitoral de um projeto político marcado pelo autoritarismo social ${ }^{4}$ e pela radicalização da agenda econômica neoliberal dá novos contornos ao papel da participação social hoje. Uma das características desse projeto político é a postura anti-establishment e a profunda descrença na política como forma de negociar diferenças e resolver problemas. A força desse projeto está na mobilização da opinião pública em torno de um inimigo comum que sintetize a luta simbólica do "cidadão de bem" contra o "errado", o "tudo-isso-que-está-aí". Para os adeptos desse projeto político, não há necessidade de espaços de participação junto ao Estado, porque a pluralidade e o dissenso não são bem-vindos. A participação social, se é que podemos chamá-la assim, deve limitar-se ao coro estridente de vozes que interagem nas redes sociais, configurando uma participação atomizada cujas decisões políticas não são calcadas no debate público, mas na popularidade das opiniões pessoais emitidas por figuras públicas, medidas através do número de curtidas, descurtidas e compartilhamentos.

Assim, diante dessa conjuntura de crescimento do autoritarismo no País, como podemos pensar a apropriação dos espaços de gestão participativa das cidades hoje? Qual é a relevância desses espaços para as estratégias de luta de movimentos e ativismos urbanos? Neste artigo, defendemos que os espaços de participação institucional são arenas de disputa que devem ser ocupadas pelos movimentos urbanos de forma a promover avanços e/ou evitar retrocessos. Contudo, essa participação junto ao Estado deve ser guiada por uma perspectiva estadocrítica, isto é, pelo entendimento dos diferentes interesses em jogo e do desequilíbrio de poder na relação entre os diferentes atores sociais e Estado (Souza, 2006; 2012a; 2012b).

Em consonância com Souza, defendemos a complementaridade crítica entre o que o autor chama de ação direta e luta institucional. A primeira significa "o conjunto de práticas de luta que são, basicamente, conduzidas apesar do Estado ou contra o Estado, isto é, sem vínculo institucional ou econômico imediato com canais e instâncias estatais" (Souza, 2012a); enquanto a segunda designa "o uso de canais, instâncias e recursos estatais, tais como 
conselhos gestores, orçamentos participativos ou fundos públicos" (ibid.). Para o autor, a luta institucional deve subordinar-se à ação direta e ser feita com cautela e prudência a partir da análise da conjuntura política. Essa atuação crítica junto ao Estado seria marcada pela dialética entre tática e estratégia, podendo revelar contradições e dilemas presentes na estrutura do Estado.

Essa perspectiva de complementaridade entre luta institucional e ação direta também está presente nas análises de Cornwall e Miraftab ${ }^{5}$ que apontam que a ação coletiva de movimentos populares transita entre espaços convidados de cidadania (invited spaces of citizenship) e espaços inventados de cidadania (invented spaces of citizenship). Ambas as autoras utilizam uma concepção de cidadania centrada na agência dos sujeitos (agency-centered), ultrapassando abordagens focadas na noção formal de pertencimento a um Estado-nação (state-centered) (Varsanyi, 2006). Essa concepção centrada na agência baseia-se em um processo de subjetivação e apropriação da ideia de cidadania por sujeitos políticos cuja experiência é marcada pelo confronto com uma realidade material de pobreza, violência, desigualdade e discriminação (Appadurai e Holston, 1996; Holston, 1999). Assim, esses espaços de cidadania propostos pelas autoras seriam arenas políticas nas quais esses sujeitos imbuídos de cidadania negociam com, contestam e/ou desafiam o Estado com o objetivo de lutar por melhores condições de vida.

Nesse sentido, espaços convidados de cidadania são aqueles legitimados pelo Estado (conselhos de políticas, tribunais de justiça, secretaria de políticas públicas, etc.) e que são ocupados por organizações populares, com o objetivo de publicitar o dissenso e negociar mecanismos de colaboração e acordo (Cornwall, 2004; Miraftab, 2004). Espaços inventados de cidadania são, por sua vez, práticas de cidadania insurgente, criadas por organizações populares (protestos, ocupações, desobediência civil, etc.) nas quais a participação social "desafia o status quo na esperança de uma transformação maior da sociedade e na resistência a relações de poder dominantes" (Miraftab, 2004, p. 1). Referindo-se a esse mesmo tipo de arena como "espaços populares" (popular spaces), Cornwall (2004, p. 2) aponta para a existência de espaços nos quais as pessoas se auto-organizam para "produzir seus próprios serviços ou por solidariedade e ajuda mútua". Assim como a ação direta e a luta institucional, esses espaços convidados e inventados de prática de cidadania são complementares - as organizações populares movem-se entre eles, tirando partido das diferentes oportunidades ao longo de suas lutas.

Na próxima seção, apresentamos o caso dos movimentos de sem-teto do Centro de São Paulo, destacando suas práticas de luta institucional e ação direta no processo de luta por moradia social na região central de São Paulo. A dinâmica de interação dos movimentos com o Estado revela o papel ambíguo deste na repressão ou viabilização das demandas dos movimentos sociais e demonstra que a luta institucional e a ação direta são complementares para fazer avançar a agenda da moradia social no Centro. 


\section{Moradia, participação e ocupação no Centro de São Paulo}

\section{A questão da moradia no Centro}

O Centro de São Paulo apresenta uma cruel combinação de vacância e precariedade habitacional que evidenciam tanto a ausência de ações sistemáticas de combate à especulação imobiliária, como a ineficácia da política habitacional para a população pobre. Apenas nos distritos da Sé e da República, por exemplo, há cerca de 500 imóveis vagos ou subutilizados notificados pela Prefeitura, o que representa uma média de aproximadamente um imóvel vago por quarteirão (PMSP, 2017). ${ }^{6}$ Essa vacância significativa contrasta, por sua vez, com a grande demanda por moradia social na região central. Segundo estimativas da Prefeitura, o município possui mais de 80.000 famílias morando em edificações encortiçadas, a maioria delas localizada na região central (PMSP, 2016).

Figura 1 - Centro de São Paulo: imóveis vagos/subutilizados notificados pela Prefeitura, Hotel Cambridge e entorno (2017)

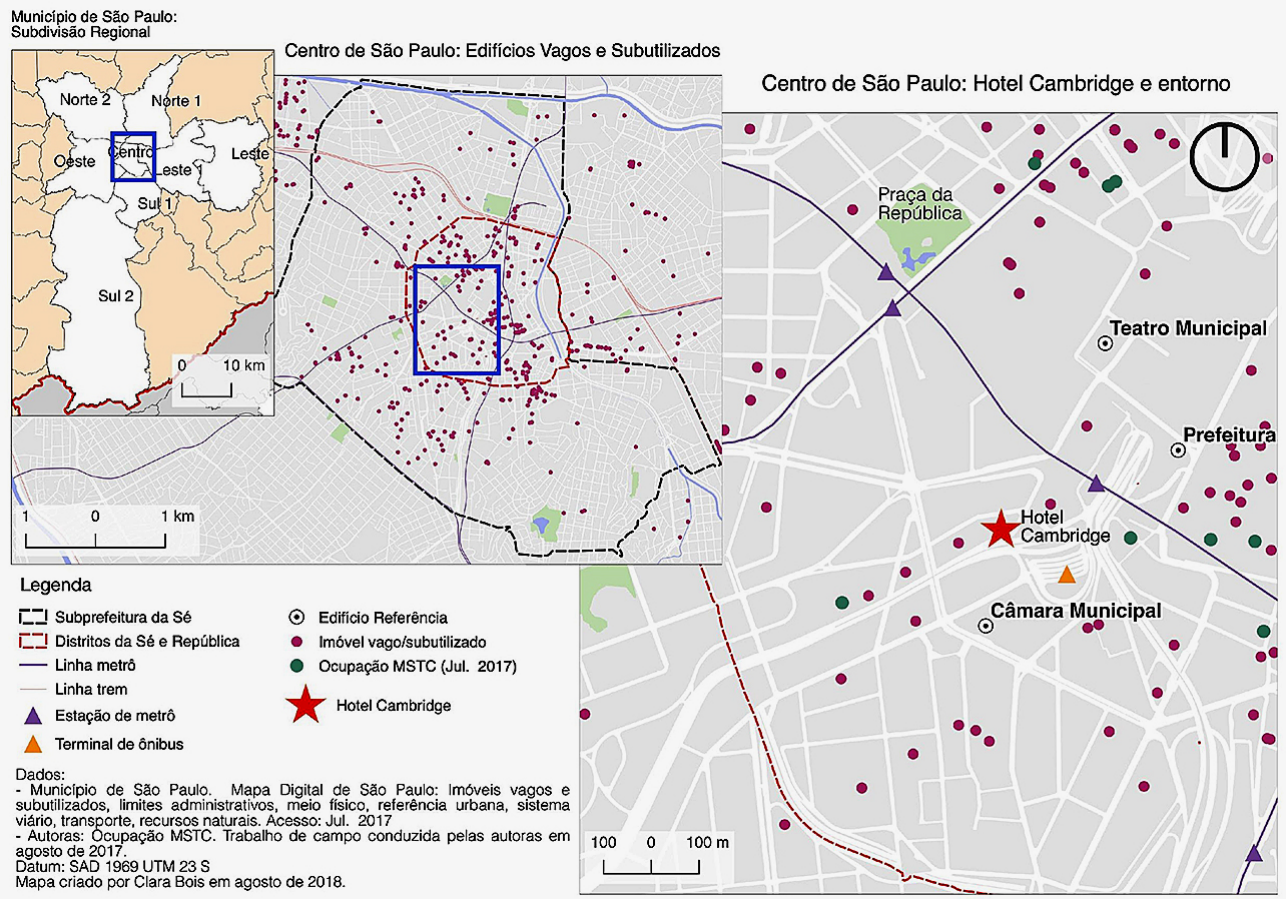

Fonte: Prefeitura Municipal de São Paulo e trabalho de campo conduzido pelas autoras. 
Esse alto número de moradias encortiçadas no Centro não é fortuito quando consideradas a qualidade da infraestrutura e dos serviços públicos na região, a concentração das oportunidades de trabalho na área central e a enorme demanda por moradia social na região metropolitana como um todo. Em que pese a significativa melhora dos serviços urbanos nos bairros periféricos da metrópole paulistana nas últimas décadas, o Centro e as áreas periféricas mais consolidadas apresentam infraestrutura e serviços públicos de meIhor qualidade do que os novos bairros e assentamentos populares da periferia (Marques, 2014). Além disso, a concentração de empregos na região central faz com que a maioria dos trabalhadores do município se desloque diariamente da periferia para o Centro de São Paulo. Dados do governo estadual apontam que a região central - incluindo o centro expandido - concentra cerca de $64 \%$ dos postos de trabalho do município, enquanto abriga cerca de $20 \%$ do total de domicílios da capital (Seade, 2017). Por fim, a Região Metropolitana de São Paulo apresenta um déficit de 639.000 habitações, aproximadamente $9 \%$ do total de domicílios da metrópole (FJP, 2018). Apenas na cidade de São Paulo, estima-se que cerca de $80 \%$ das famílias que compõem o déficit habitacional do município apresenta renda familiar inferior a 3 salários-mínimos e necessitam de alguma forma de assistência para moradia (PMSP, 2016).

Assim, consideradas a desigualdade socioespacial da metrópole paulistana e a pouca efetividade da política pública de habitação focada na população pobre, não é surpreendente que uma parcela da classe trabalhadora mais pobre viva precariamente em edificações encortiçadas em troca da maior facilidade de acesso aos polos de emprego e serviços públicos. Nesse sentido, as organizações de moradores de cortiços foram as primeiras a colocar a demanda por moradia social no Centro para o governo do município, constituindo, assim, o embrião dos movimentos de sem-teto.

Participação institucionalizada e ocupação: o DNA dos movimentos de sem-teto no Centro de São Paulo

Para se compreender a atuação dos movimentos de sem-teto do Centro de São Paulo é importante retomar o seu surgimento a partir das organizações de base ligadas aos moradores de cortiços. No final dos anos 1970, organizações do movimento sindical que mobilizavam operários na região da Mooca perceberam que muitas das demandas apresentadas pelos trabalhadores tangenciavam a questão da moradia no Centro, uma vez que, para ficarem mais perto do local de trabalho, boa parte desses operários fixava residência nos cortiços da região. Segundo Manoel Del Rio (apud Aquino, 2010), ${ }^{7}$ inicialmente, os problemas apresentados por esses trabalhadores giravam em torno dos serviços públicos, como a necessidade de creches ou o preço alto da energia elétrica. A reivindicação por moradia tornou-se mais evidente a partir da crise econômica dos anos 1980, quando muitos residentes dos cortiços ficaram desempregados. Assim, essas organizações sindicais também passaram a mobilizar os trabalhadores da Mooca em relação a problemas ligados à habitação e a pressionar o poder público por melhorias nas condições de moradia dentro dos cortiços. Essas lutas foram as primeiras a demandar do Estado políticas de habitação social específicas para o Centro de São Paulo (Aquino, 2010). 
No final dos anos 1980, durante a administração de Luiza Erundina (PT), a prefeitura tornou-se mais aberta à participação dos movimentos sociais na administração pública. 0 contexto político mais favorável ao diálogo permitiu que demandas dos movimentos de cortiços - como a construção de moradia popular no Centro de São Paulo - passassem a reverberar dentro do Estado. Todavia, as eleições consecutivas de dois políticos conservadores para a Prefeitura de São Paulo - Paulo Maluf e Celso Pitta (ambos filiados ao Partido Progressista Brasileiro, PPB) - paralisaram o desenvolvimento da política de habitação popular no Centro durante boa parte da década de 1990. Assim, em 1997, duas organizações de moradores de cortiços - o Fórum de Cortiços e a Unificação da Luta de Cortiços (ULC) - passam a ocupar edifícios vagos no Centro como forma de chamar a atenção do Estado e do público em geral para o problema da moradia em São Paulo.

Como apontado por Neuhold (2009), a ocupação de imóveis vagos não era uma ação propriamente nova dentro do movimento de moradia. No entanto, pela primeira vez, as ocupações eram coordenadas e organizadas como ações contínuas que propunham uma agenda de políticas para a habitação. Segundo a autora, os movimentos passaram a selecionar estrategicamente imóveis que estavam vazios há bastante tempo e possuíam dívidas acumuladas com a Prefeitura de São Paulo. Depois de ocuparem os imóveis, os movimentos entravam em negociação com o Estado e expunham suas demandas por novos programas de habitação, bem como pelo direito de participar no controle e na formulação da política habitacional. Havia, portanto, uma expectativa de que a ação calcada no conflito com o Estado gerasse uma ampliação nos canais de diálogo junto a ele, de forma a aumentar a influência dos movimentos na elaboração das políticas de moradia. Como bem aponta Blikstad (2012), incidir na política pública estava no DNA do movimento dos sem-teto.

Além disso, os movimentos reconhecem que o suporte político e financeiro do Estado é estratégico para os sem-teto permanecerem nas ocupações organizadas e, eventualmente, garantirem a posse do imóvel. Assim, a interação com o Estado possibilita o aproveitamento de possíveis janelas de oportunidade que facilitem a criação e/ou implementação de políticas, bem como a captação de recursos. 0 caso da ocupação do Hotel Cambridge, organizada pelo Movimento dos Sem-Teto do Centro (MSTC) ${ }_{1}^{8}$ ilustra bem essa interação dos movimentos com o Estado. ${ }^{9}$

Segundo Carmen Silva, ${ }^{10}$ em meados dos anos 2000, o MSTC apontou o Hotel Cambridge para o governo municipal com o objetivo de que ele utilizasse o imóvel no reassentamento das famílias despejadas da Ocupação Prestes Maia: ${ }^{11}$

[...] quando nós indicamos esse prédio para a gestão do Kassab, ${ }^{12}$ nós estávamos à procura de imóveis no Centro de São Paulo, [...] para que o Prefeito comprasse e desapropriasse para atender a primeira demanda Prestes Maia. Essa procura é feita por nós mesmos, a gente vai atrás, puxa a certidão, a gente procura sempre pelo imóvel sem a função social da propriedade. (Carmen Silva apud Braconi, 2017, pp. 136-137)

Apesar de ter sido desapropriado em 2011, a demora no encaminhamento do edifício para as famílias sem-teto levou o MSTC a ocupar o Hotel Cambridge em 2012. No ano seguinte, já durante a administração Fernando 
Haddad (PT), a Companhia Metropolitana de Habitação de São Paulo (Cohab-SP) entrou com uma ação de reintegração de posse do imóvel com o objetivo de viabilizar uma parceria público-privada. O MSTC conseguiu evitar o despejo, após negociar um acordo com a Secretaria Municipal de Habitação (Sehab), garantindo a permanência das famílias sem-teto, bem como a destinação do edifício para a habitação de interesse social.

0 acordo firmado entre a Prefeitura e o movimento não impediu que a Cohab-SP continuasse pressionando o poder executivo para mudar a destinação do edifício. Santo Amore et al. (2015) relatam que, em 2015, a companhia tentou passar no Conselho Municipal de Habitação (CMH) duas moções de voto, propondo utilizar o Hotel Cambridge numa parceria público-privada para a construção de unidades habitacionais (PPP-habitacional). De acordo com a proposta, o poder público cederia o imóvel para a iniciativa privada construir 121 unidades habitacionais cuja destinação seria dividida em 48 unidades para habitação de interesse social (renda familiar de até 5 salários-mínimos) e 73 unidades para habitações de mercado popular (renda familiar entre 5 e 10 salários-mínimos). 0 parceiro privado ficaria livre para comercializar as unidades voltadas para o mercado popular, enquanto a Prefeitura receberia as unidades de habitação social como contrapartida. Ou seja, além de não dedicar a integralidade das unidades habitacionais produzidas para a população de baixa renda, a proposta da Cohab-SP não priorizaria o atendimento dos sem-teto que já moravam no Cambridge, uma vez que a seleção dos moradores das unidades de habitação social seria feita pela Prefeitura, em vez de conduzida pelo MSTC.
Apesar das seguidas investidas da Cohab-SP, o movimento conseguiu barrar a proposta da PPP-habitacional, por meio de sua participação no Conselho Municipal de Habitação. Ironicamente, a própria Cohab-SP, através do edital de chamamento n. 002/2015, selecionou o MSTC para empreender o retrofit (conversão do imóvel para o uso de moradia) do Hotel Cambridge, por meio de recursos do Programa Minha Casa Minha Vida-Entidades (MCMV-Entidades). ${ }^{13}$ No final de 2016, a Prefeitura transferiu a posse do imóvel para o movimento, selando o fim do risco de despejo. No princípio de 2019, o MSTC iniciou as obras de retrofit do imóvel que se chamará Residencial Cambridge e contará com 121 unidades de habitação de interesse social (OcupaNews, 2019). ${ }^{14}$

O caso da Ocupação do Hotel Cambridge mostra uma interação constante entre o movimento e o Estado. Essa interação é marcada tanto pelo conflito que, em última instância, levou o MSTC a ocupar o Hotel Cambridge; como pela negociação, como no aproveitamento do suporte político e financeiro da Prefeitura para viabilizar a reforma do imóvel através do MCMV-Entidades. Essa dinâmica revela o papel ambivalente do Estado que atua, por um lado, na repressão dos movimentos sociais e na manutenção do status quo, e, por outro lado, atende às demandas desses movimentos.

\section{Movimentos de sem-teto e a relação com o Estado}

A atuação dos movimentos de sem-teto de São Paulo revela as nuanças da participação social institucionalizada no contexto da 
política de habitação da cidade. As ocupações de edifícios vagos e subutilizados organizadas por esses movimentos denunciam a especulação imobiliária no Centro de São Paulo e problematizam, de forma radical, a falta de moradia digna para a população pobre da capital paulista, experimentando práticas auto-organizadas no uso, gestão e transformação dos espaços que podem transformar o desenho da política de habitação.

Além da ocupação como ação direta, os movimentos de sem-teto do Centro de São Paulo utilizam a participação institucionalizada para pautar as suas demandas junto ao Estado, fazendo uso tanto de espaços inventados quanto de espaços convidados de cidadania. No caso específico do MSTC, o movimento foi capaz de obstruir a proposta da PPP-habitacional, por meio de sua participação no Conselho Municipal de Habitação, e, posteriormente, viabilizar a reforma do Hotel Cambridge, inicialmente ocupado, com uso de recursos do MCMV-Entidades.

Tendo em vista que um dos objetivos centrais dos movimentos é transformar a agenda da moradia social no Centro em uma política de habitação consistente e efetivamente implementada pelo Estado, é imprescindível que eles pautem, nos espaços de participação institucionalizada, as suas demandas e propostas. Os movimentos de sem-teto entendem como primordial estarem presentes nos canais de participação do Estado, como os conselhos de habitação, saúde, direitos da criança e do adolescente, entre outros (Blikstad, 2012; Tatagiba, Paterniani e Trindade, 2012). Ocupações e participação institucional são, nesse contexto, marcadas por uma visão estratégica dos movimentos no que diz respeito à relação entre suas demandas e a política de habitação municipal. Esse tipo de atuação articula ação direta e luta institucional, combinando práticas de curto prazo com práticas de longo prazo e revelando a dialética discutida por Souza (2006, 2012a, 2012b) entre abordagens táticas (no contexto de uma determinada conjuntura) e estratégicas (que visam a transformações estruturais).

As ocupações caracterizam-se como uma ação controversa, cuja legitimidade é frequentemente questionada pelo Estado e por setores da sociedade. Sua legalidade, por exemplo, é objeto de disputa no campo jurídico. Para os sem-teto e demais defensores da agenda de reforma urbana, a legalidade das ocupações está garantida nos Art. 5ㅇ (XXII e XXIII) e 6ㅇda Constituição Federal, que estabelecem, respectivamente, a função social da propriedade e o direito à moradia. De acordo com esse ponto de vista, duas razões fundamentais embasam a legitimidade das ocupações. Primeiro, os moradores sem-teto engajam-se nas ocupações organizadas por necessidade - não por má-fé -, uma vez que o Estado não é capaz de garantir o direito à moradia aos mais pobres. Segundo, as propriedades vazias ocupadas pelos movimentos sem-teto descumprem o princípio da função social, ao servirem prioritariamente ao enriquecimento dos proprietários através da especulação imobiliária. Assim, para os movimentos de sem-teto, as ocupações são ao mesmo tempo uma forma de denúncia e de solução; elas dão visibilidade ao problema da especulação imobiliária e da falta de moradia para os mais pobres na cidade de São Paulo, recuperam a função social de imóveis em estado de abandono e fazem as vezes do Estado, ao fornecer uma alternativa de moradia popular à população pobre da cidade. 
Silva, Comarú e Silva (2018) apontam, todavia, que essa interpretação sobre a função social da propriedade e o direito à moradia é controversa dentro do Judiciário. Frequentemente, juízes e desembargadores optam por garantir o direito à propriedade, ainda que ela não cumpra sua função social. Já o entendimento sobre o direito à moradia é controverso devido à dimensão ampla do tema que é abordado de maneira sucinta pela Constituição. Segundo os autores, a lei não enuncia a forma com que o direito à moradia deve ser entendido nem estabelece de maneira clara o papel do Estado na sua implementação. Tal indefinição sobre o conteúdo do direito à moradia dá margem a contendas não apenas no campo jurídico, como também nas arenas social e política, em ainda se disputam a legitimidade e efetivação desse direito.

No âmbito da política institucional, as ocupações também são controversas e, muitas vezes, conflitam com o planejamento do Estado no que diz respeito ao uso da terra na área central. Como apontado anteriormente, a destinação da totalidade do Hotel Cambridge para a produção de habitação de interesse social foi objeto de disputa dentro do Conselho Municipal de Habitação. Santo Amore et al. (2015) destacam, por exemplo, o rol de sensos comuns enumerados pelos representantes da Cohab-SP, a fim de justificar a adoção da PPP-habitacional: a impossibilidade de a Prefeitura usar recursos públicos para viabilizar programas moradia de baixa renda no Centro; a necessidade de se construir parcerias com o setor privado para viabilizar esse tipo de programa; o alto custo de oportunidade de destinar, para o estoque de habitação social, um imóvel localizado numa área central, uma vez que "com os recursos oriundos da operação, poder-se-ia adquirir terrenos na periferia e outros imóveis e produzir mais unidades de habitação social" (ibid.). Ou seja, para uma parte do Estado, usar imóveis bem localizados para atender à demanda de habitação para baixa renda seria um desperdício de recursos.

A proposta de reformar o Hotel Cambridge via parceria público-privada também reflete uma tendência mais ampla da política de habitação do estado e do município de São Paulo, que tem priorizado a formação de parcerias com o setor privado para a produção de habitação de interesse social. Uma das iniciativas mais amplas nesse sentido é a PPP-habitacional do Centro, que concede, ao setor privado, a implantação e a administração de mais de 14.000 unidades habitacionais de interesse social e de mercado popular na região central de São Paulo (Santoro, 2014). Apesar do discurso de ampliação de oportunidades de moradia para a população pobre no Centro, a PPP-habitacional não é um projeto inclusivo. A implementação dessa parceria na região da Estação da Luz, por exemplo, tem sido marcada pela violência do Estado contra a população mais vulnerável da região, incluindo o uso extensivo da força policial, a emissão ilegal de ordens de despejo de moradores e comerciantes e a demolição expressa de imóveis com o objetivo de liberar o espaço para a implementação do projeto urbano pela iniciativa privada. ${ }^{15}$ Além disso, as mais de 3.800 moradias previstas na proposta dificilmente beneficiarão a população dos cortiços, pensões e ocupações de sem-teto da região, uma vez que são habitações destinadas a famílias que possuem trabalho formal no Centro e renda de até 10 salários mínimos. Como os residentes mais vulneráveis da Luz não possuem trabalho formal nem fonte de renda fixa, é provável que a 
implementação da PPP-habitacional contribua para a expulsão desses moradores da região (Lins e Rolnik, 2018). ${ }^{16}$

Além da resistência à implementação de uma política de moradia no Centro direcionada à população que se encontra em situação de vulnerabilidade social, os movimentos de sem-teto também enfrentam a criminalização das ocupações organizadas (e de seus ocupantes) por setores da sociedade. Com frequência, partes do Estado, da mídia e da sociedade civil referem-se aos sem-teto como meros invasores que violam o direito à propriedade privada. Os movimentos, por sua vez, enfatizam que seus assentamentos são ocupações organizadas e se colocam disponíveis para o diálogo e a negociação com o poder público. ${ }^{17}$ Nesse sentido, a presença de membros dos movimentos de sem-teto em instituições do Estado - seja nos conselhos de políticas públicas, seja nos tribunais de justiça - é também uma forma de reforçar que seus integrantes são sujeitos autônomos, imbuídos de cidadania e que possuem demandas legítimas baseadas em direitos ratificados pela Constituição.

No Brasil, em que pese o histórico de pressão popular para a institucionalização de diversos espaços e mecanismos de participação, a participação social adquiriu muitas vezes um caráter legitimador de decisões tecnocráticas que canalizavam os interesses de grupos social, econômico e politicamente privilegiados. No entanto, apesar dos seus limites, essa participação institucionalizada pode abrir brechas para agendas e ações que auxiliem na melhoria das condições de vida de grupos social e economicamente vulneráveis. Por um lado, o caso dos movimentos de sem-teto do Centro de São Paulo demonstra que a participação junto ao Estado é insuficiente para tornar a habitação um direito concreto e universalizado (Neuhold, 2009; Blikstad, 2012), o que reforça a necessidade de se engajar na ocupação como ação direta. Por outro lado, a inserção dos movimentos nas arenas do Estado é importante por reiterar a legitimidade da pauta da moradia popular no Centro, possibilitando eventuais ganhos, como no caso da destinação do Hotel Cambridge para a moradia social.

\section{Assegurando espaços de participação: consolidando propostas junto à política institucional?}

Como pensar o significado das arenas de participação social para ativismos e movimentos hoje? Qual é a relevância dessas arenas, considerando os limites e as contradições apontados ao longo deste trabalho? Por um lado, o avanço de um projeto político calcado no autoritarismo social e na radicalização do neoliberalismo econômico impõe a necessidade de os ativismos e movimentos urbanos reforçarem as práticas socioespaciais que ocorrem independentemente dos espaços concedidos pelo Estado, estabelecendo pontes entre lutas locais, regionais e nacionais. Por outro lado, a atuação desses movimentos junto ao Estado se mostra crucial do ponto de vista estratégico, o que significa preservar a autonomia de suas práticas ao mesmo tempo que se busca garantir ganhos junto ao Estado, por meio da inserção de suas agendas no âmbito da política urbana e habitacional. 
O crescimento dos espaços de participação social após a aprovação da Constituição de 1988 indicava a continuidade de um processo de construção democrática que - ainda que lento, heterogêneo, acidentado e, em certos casos, pouco aprofundado - parecia progressivo. Se a participação institucionalizada revelou seus limites ao funcionar como um meio de legitimação de decisões já tomadas em outras instâncias, abafando conflitos ao invés de evidenciá-los e desgastando a força propositiva dos movimentos sociais; a institucionalização desses espaços convidados de cidadania facilitou o engajamento dos movimentos na luta institucional e passou a exigir desses mesmos movimentos uma postura crítica, consciente dos diferentes interesses em jogo e do desequilíbrio de poder, com relação à participação nesses espaços. Assim, participação social e ação direta não são práticas mutuamente excludentes no âmbito do repertório de ação dos movimentos sociais. Pelo contrário, a ação coletiva transita entre os espaços de participação inventados e convidados e articula-se à luta institucional a partir da consciência dos seus limites, o que implica a abordagem dialética dos conjuntos tática/estratégia, conjuntura/estrutura e curto/longo prazos (Souza, 2012a; 2012b).

A luta dos movimentos de sem-teto por moradia digna e pelo direito à cidade em São Paulo apresenta um conjunto de práticas que combinam ação direta (reivindicação, ocupação e autogestão dos edifícios) e a articulação com instâncias do Estado no sentido de pautar demandas e implementar ações que façam a agenda da moradia social no Centro avançar. Nesse sentido, o caso da ocupação do Hotel Cambridge mostra exatamente como o MSTC usou tanto os espaços de participação institucional (Prefeitura, Conselho de Habitação, MCMV-Entidades), como os espaços inventados de cidadania, para viabilizar a conversão do imóvel em habitação de interesse social.

Num contexto de crescimento do autoritarismo do Estado brasileiro, parece urgente a elaboração de estratégias de luta que articulem ação direta e inserção de demandas populares junto ao Estado, assumindo a participação social como elemento fundamental para a retomada do projeto democrático. Em outras palavras, o momento atual aponta para a necessidade de estratégias de luta que evitem o desmanche das estruturas de participação social - que garantem alguma entrada dos movimentos nas decisões do Estado -, que aprimorem os espaços de participação já existentes e que pressionem pela criação de novos espaços. Afinal, como bem aponta Dagnino (apud Teixeira e Trindade, 2018, p. 273), "qualquer proposta de reconfiguração do Estado que não incorpore e aprofunde a participação da sociedade no poder decisório só reforçará o retrocesso democrático".

Nesse sentido, uma questão crucial a ser enfrentada pelos movimentos sociais e ativismos urbanos contemporâneos é a de como fazer a luta institucional ao passo em que a auto-organização e as práticas de autogestão são também desenvolvidas no cotidiano. Sem ter a pretensão de oferecer respostas conclusivas para essa questão, colocamos dois pontos importantes para reflexão. Primeiro, é necessário haver clareza com relação ao projeto político defendido e posto em prática tanto nos espaços inventados quanto nos espaços convidados de cidadania. Mesmo nos casos em que os movimentos se identifiquem em termos político-partidários com atores no comando 
do Estado, é necessário distinguir o projeto político do movimento daquele defendido pelo partido no governo, de forma a garantir uma participação institucional crítica e com visão de longo prazo, capaz de consolidar propostas junto à política institucional e de pressionar continuamente a democratização das estruturas do Estado.

Em segundo lugar, é preciso atenção ao surgimento de novas confluências perversas, isto é, a novas disputas políticas sobre o domínio do discurso em torno de determinados conceitos. No campo da luta pelo direito à moradia, por exemplo, o discurso acerca da provisão da habitação de interesse social tem se limitado à construção de novas unidades através da formação de parcerias com o setor privado via PPPs-habitacionais e contrapartidas em projetos de operação urbana consorciada, entre outras formas de associação. A vinculação da pauta da moradia social à produção de novas unidades tem retirado, da agenda de discussão, outras formas de provisão habitacional - como o aluguel social ou a assistência técnica popular - que não incluem necessariamente a promoção da propriedade privada nem a atuação direta das empresas construtoras. Além disso, o mantra em torno da criação de parcerias com o setor privado tem relativizado o papel do Estado na garantia do direito à habitação e no controle sobre o uso da terra, permitindo que o setor imobiliário continue excluindo ou expulsando a população pobre e em situação de vulnerabilidade social das localizações centrais das cidades.

Se, no início dos anos 2010, concordamos com Souza (2012b) que "a ação direta é uma necessidade; a luta institucional, uma possibilidade"; no contexto atual, em que os espaços de participação legitimados pelo Estado tendem a perder a sua relevância e as suas condições de existência, parece crucial imaginar possibilidades de articulação entre ação direta e luta institucional no sentido de garantir os pontos de diálogo e, ao mesmo tempo, explicitar os conflitos entre movimentos urbanos e forças do Estado. Os movimentos de sem-teto do Centro de São Paulo mostram que a participação nos espaços institucionais é crucial para o processo de luta pelo direito à moradia, uma vez que possibilita a inserção da agenda dos movimentos sociais na pauta das instituições de planejamento e gestão das cidades e cria condições para o aprofundamento da democracia nos processos de tomada de decisão na produção do espaço urbano.

\section{[I] https://orcid.org/0000-0001-8017-2934}

University of California, Los Angeles. Luskin School of Public Affairs, Department of Urban Planning. Los Angeles, California, United States.

claramsbois@ucla.edu

\section{[II] https://orcid.org/0000-0002-8892-3947}

Universidade Federal de Minas Gerais, Escola de Arquitetura e Urbanismo, Grupo Morar de Outras Maneiras. Belo Horizonte, MG/Brasil.

ligia.milagres@gmail.com 


\section{Notas}

(1) Para uma discussão aprofundada sobre os limites da atuação institucional pró-reforma urbana, ver Maricato (2011) e Klink e Denaldi (2016).

(2) A eleição de Bolsonaro para a presidência da república em 2018 é, provavelmente, o maior caso de sucesso do ultraconservadorismo no Brasil, desde o retorno do regime democrático. Para um perfil de Jair Bolsonaro, ver Diegues (2016).

(3) Ver, por exemplo, a exposição de motivos para a aprovação do Decreto n. 9.759/2019, que extingue a Política e o Sistema Nacional de Participação Social. Dentre as razões elencadas pelo então Ministro da Casa Civil, Onyx Lorenzoni, destacam-se o "grande gasto homem/hora de agentes públicos em constantes reuniões de colegiados" e a atuação de "grupos de pressão [...] que se utilizam de colegiados [...] para tentar emplacar pleitos que não estão conforme a linha das autoridades eleitas democraticamente" (Lorenzoni, 2019, pp. 1-2).

(4) Utilizamos aqui a definição de Dagnino, Olvera e Panfichi (2006, p. 48) que descrevem o autoritarismo social como uma face do autoritarismo que permeia a sociedade latino-americana, representando "uma cultura que legitima as diferenças sociais, que internaliza os códigos que hierarquizam as classes e os grupos sociais e os organizam em categorias com base em seu pertencimento de classe, raça, gênero, região e país" e, acrescentaríamos, orientação sexual.

(5) Principalmente Cornwall (2004) e Miraftab (2004; 2009). Ver, também, Cornwall (2002) e Miraftab e Wills (2005).

(6) Os imóveis notificados incluem tanto edifícios inteiros (prédios de escritório, hotéis, etc.), como unidades de apartamentos, lojas, galpões, etc.

(7) Manoel Del Rio foi militante do movimento sindical e um dos fundadores da Associação dos Trabalhadores da Mooca. Também ajudou a fundar a Frente de Luta pela Moradia (FLM), uma coalizão de movimentos de sem-teto estruturada na reivindicação do direito à moradia digna na Região Metropolitana de São Paulo.

(8) O Movimento dos Sem-Teto dos Centro (MSTC) é uma organização de sem-tetos que atua na cidade de São Paulo. O movimento foi fundado em 2000 a partir de uma dissidência do movimento de cortiços. Desde então, o MSTC organiza pessoas de baixa e baixíssima renda na ocupação de imóveis vagos e subutilizados majoritariamente localizados no Centro. Segundo a coordenadoria do MSTC, em 2017, o movimento organizava 12 ocupações - 10 delas localizadas no centro - que abrigavam cerca de 900 famílias (comunicação pessoal, agosto de 2017).

(9) Sobre o processo de ocupação do Hotel Cambridge e o uso do seu espaço pelas famílias, ver Stevens (2017).

(10) Carmen Silva ajudou a fundar o MSTC e, atualmente, está na coordenação do movimento.

(11) A Ocupação Prestes Maia é a maior ocupação organizada por sem-tetos na América Latina, abrigando cerca de 480 famílias (Santandreu, 2018). A Ocupação recebeu inúmeras ordens de despejo, uma delas efetivamente executada em 2007. Em 2010, o movimento de sem-teto ocupou novamente o edifício, uma vez que ele havia permanecido inutilizado. Em 2015, a Prefeitura desapropriou o imóvel com o fim de transformá-lo em habitação de interesse social para as famílias ocupantes (Redação RBA, 2015). 
(12) Gilberto Kassab (Democratas, DEM/Partido Social Democrático, PSD) governou a cidade de São Paulo no período de 2006 a 2013.

(13) O MCMV-Entidades é uma modalidade especial do Programa Minha Casa Minha Vida destinada à produção habitacional para a famílias de baixa e baixíssima renda, através de empreendimentos geridos pelos movimentos de moradia.

(14) Outro fator crucial para viabilizar o empreendimento é a parceria histórica entre o MSTC e a assessoria técnica Peabiru que desenvolveu o projeto de reabilitação do edifício.

(15) Dois eventos dramáticos que marcaram a implementação da PPP-habitacional na região da Luz foram a operação policial que desbaratou a concentração de usuários de drogas conhecida como Cracolândia e a demolição de uma pensão com moradores dentro, ambos incidentes ocorridos em maio de 2017.

(16) Para uma discussão mais aprofundada sobre as PPPs para a produção de HIS em São Paulo, ver Santoro, Lima e Mendonça (2018). Sobre os conflitos na região da Luz e o impacto da PPP-habitacional nessa região, ver Lins e Rolnik (2018).

(17) Carmen Silva, comunicação pessoal, agosto de 2017.

\section{Referências}

APPADURAI, A.; HOLSTON, J. (1996). Cities and citizenship. Public Culture, v. 8, n. 2, pp. 187-204.

AQUINO, C. R. F. D. (2010). A construção do Centro de São Paulo como arena política dos movimentos de moradia. Disponível em: https://journals.openedition.org/pontourbe/1556. Acesso em: 30 set 2016 .

BOIS, M. C. M. S. (2013). Conselho Municipal de Habitação de Belo Horizonte e o poder sobre a deliberação das diretrizes, planos e programas da Política Municipal de Habitação. Dissertação de mestrado. Belo Horizonte, Universidade Federal de Minas Gerais.

BLIKSTAD, K. D. (2012). O agir coletivo nas interfaces da sociedade civil e do sistema político: o caso da atuação do movimento de moradia de São Paulo sobre a política pública de habitação. Dissertação de mestrado. Campinas, Universidade Estadual de Campinas.

BRACONI, J. C. (2017). A disputa pela moradia na região central de São Paulo: uma análise das ocupações Prestes Maia, Mauá e Cambridge. Dissertação de mestrado. São Paulo, Universidade de São Paulo.

BRASIL (1988). Constituição da República Federativa do Brasil de 1988. Disponível em: http://www. planalto.gov.br/ccivil_03/constituicao/constituicaocompilado.htm. Acesso em: 1o abr 2019.

CALDEIRA, T. P.; HOLSTON, J. (2015). Participatory urban planning in Brazil. Urban Studies, v. 52, n. 11, pp. 2001-2017.

CAVALCANTI, G. C. V. (2006). Uma concessão ao passado: trajetórias da união dos movimentos de moradia de São Paulo. Dissertação de mestrado. São Paulo, Universidade de São Paulo. 
CORNWALL, A. (2002). Locating Citizen Participation. IDS Bulletin. Brighton, v. 33, n. 2, pp. I-X.

(2004). Introduction: New Democratic Spaces? The Politics and Dynamics of Institutionalised Participation. IDS Bulletin. Brighton, v. 35, n. 2, pp. 1-10.

DAGNINO, E. (2004). Construção democrática, neoliberalismo e participação: os dilemas da confluência perversa. Política \& Sociedade. Florianópolis, v. 3, n. 5, pp. 139-164.

DAGNINO, E.; OLVERA, A.; PANFICHI, A. (2006). La Disputa por la construcción democrática en la América Latina. Cuadernos para la Democratización, v. 3. Juárez, Ciesas.

DIEGUES, C. (2016). Direita, volver: pré-candidato à presidência, Jair Bolsonaro coloca o ultraconservadorismo no jogo eleitoral. Disponível em: https://piaui.folha.uol.com.br/materia/ direita-volver/. Acesso em: 9 abr 2019.

FERNANDES, E. (2011). Implementing the urban reform agenda in Brazil: Possibilities, challenges, and lessons. Urban Forum, v. 22, n. 3, pp. 299-314.

FJP - Fundação João Pinheiro (2018). Déficit Habitacional no Brasil 2015. Belo Horizonte, Fundação João Pinheiro.

HOLSTON, J. (1999). "Spaces of insurgent citizenship". In: HOLSTON, J. (org.). Cities and Citizenship. Durham, Duke University Press.

KLINK, J.; DENALDI, R. (2016). On urban reform, rights and planning challenges in the Brazilian metropolis. Planning Theory, v. 15, n. 4, pp. 402-417.

LINS, R. D.; ROLNIK, R. (orgs.) (2018). Observatório das remoções 2017-2018: relatório bianual. São Paulo, FAU-USP.

LORENZONI, O. D. (2019). Exposição de Motivos n. 19. Disponível em: http://www.planalto.gov.br/ ccivil_03/_ato2019-2022/2019/Exm/Exm-Dec-9759-19.pdf. Acesso em: 24 abr 2019.

MARICATO, E. (2011). O impasse da política urbana no Brasil. Petrópolis, Vozes.

MARQUES, E. C. L. (2014). A metrópole de São Paulo no início do século XXI. Revista USP. São Paulo, n. 102, pp. 23-32.

(2017). Em busca de um objeto esquecido. A políticas e as políticas do urbano no Brasil. Revista Brasileira de Ciências Sociais, v. 32, n. 95, pp. 1-18.

MIRAFTAB, F. (2004). Invented and invited spaces of participation: neoliberal citizenship and feminist's expanded notion of politics. Wagadu: Journal of Transnational Women's and Gender Studies, v. 1, pp. 1-7.

(2006). Feminist praxis, citizenship and informal politics: reflections on South Africa's anti-eviction campaign. International Feminist Journal of Politics, v. 8, n. 2, pp. 194-218.

(2009). Insurgent planning: situating radical planning in the global south. Planning Theory, v. 8, n. 1, pp. 32-50.

MIRAFTAB, F.; WILLS, S. (2005). Insurgency and spaces of active citizenship: the story of Western Cape anti-eviction campaign in South Africa. Journal of Planning Education and Research, v. 25, n. 2, pp. 200-217.

NEUHOLD, R. D. R. (2009). Os movimentos de moradia e sem-teto e as ocupações de imóveis ociosos: a luta por políticas públicas habitacionais na área central da cidade de São Paulo. Dissertação de mestrado. São Paulo, Universidade de São Paulo. 
OCUPANEWS (2019). Não é sorte não, é luta. Disponível em: https://www.facebook.com/OcupaNews/ photos/a.261872540987048/547851919055774/?type=3\&theater. Acesso em: 1abr 2019.

PMSP - Prefeitura Municipal de São Paulo (2016). Plano Municipal de Habitação de São Paulo: Caderno para Discussão. Disponível em: http://www.habitasampa.inf.br/files/CadernoPMH.pdf. Acesso em: 1ㅇabr 2019.

(2017). Mapa Digital da Cidade de São Paulo: Legislação Urbana, Imóveis Notificados. Disponível em: http://geosampa.prefeitura.sp.gov.br/PaginasPublicas/_SBC.aspx. Acesso em: 2 abr 2019.

REDAÇÃO RBA - Rede Brasil Atual (2015). Haddad desapropria edifício Prestes Maia e vai destiná-lo à moradia popular. Disponível em: https://www.redebrasilatual.com.br/cidadania/2015/10/ haddad-desapropria-edificio-prestes-maia-e-vai-destina-lo-a-moradia-popular-5496.html. Acesso em: 14 mar 2019.

ROLNIK, R. (2013). Ten years of the City Statute in Brazil: from the struggle for urban reform to the World Cup cities. International Journal of Urban Sustainable Development, v. 5, n. 1, pp. 54-64.

SANTANDREU, A. (2018). Edifício Prestes Maia, o maior símbolo das ocupações na América Latina. Disponível em: https://noticias.uol.com.br/ultimas-noticias/efe/2018/05/10/edificio-prestesmaia-o-maior-simbolo-das-ocupacoes-na-america-latina.htm. Acesso em: 14 mar 2019.

SANTO AMORE, C. et al. (2015). Hotel Cambridge: por que não é possível construir HIS no centro de São Paulo? Disponível em: https://observasp.wordpress.com/2015/06/24/hotel-cambridge-por-quenao-e-possivel-construir-habitacao-de-interesse-social-no-centro-de-sao-paulo/\#more-1072. Acesso em: 6 mar 2019

SANTORO, P. F. (2014). O papel do Estado na PPP da Habitação de São Paulo. Disponível em: https:// observasp.wordpress.com/2014/11/06/o-papel-do-estado-na-ppp-da-habitacao-de-sao-paulo/. Acesso em: 13 mar 2019.

SANTORO, P. F.; LIMA, P.; MENDONÇA P. (2018). "Parcerias Públicos-Privadas e Habitação Social: Vínculos Perversos". In: ROLNIK, R. et al. (orgs.). Cidade Estado Capital: Estruturação Urbana e Resistência em Belo Horizonte, Fortaleza e São Paulo. São Paulo, FAU-USP.

SEADE - Fundação Sistema Estadual de Análise de Dados (2017). Município de São Paulo e o Mercado de Trabalho. Disponível em: http://www.seade.gov.br/produtos/midia/2017/01/MSP_ Indicadores_25jan_2.pdf. Acesso em: 1ㅇabr 2019.

SILVA, E. A.; COMARÚ, F. A.; SILVA, S. J. (2018). Direito à moradia e judicialização: atuação da Defensoria Pública Paulista. Revista Estudos de Sociologia. Araraquara, v. 23, n. 45, pp. 81-98.

SOUZA, M. L. (2006). Social movements as 'critical urban planning' agents. City, v. 10, n. 3, pp. $327-342$. (2012a). Ação direta e luta institucional: complementaridade ou antítese? (1ạ parte). Disponível em: http://passapalavra.info/2012/04/56901/. Acesso em: 6 fev 2019.

(2012b). Ação direta e luta institucional: complementaridade ou antítese? (2a parte). Disponível em: http://passapalavra.info/2012/04/56901/. Acesso em: 6 fev 2019.

STEVENS, J. (2017). “Occupied city: Hotel Cambridge and central São Paulo between urban decayand resurrection". In: CAIRNS, G.; ARTOPOULOS, G.; DAY, K. (orgs.). From conflict to inclusion in housing: interaction of communities, residents and activists. Londres, UCL Press. 
TATAGIBA, L.; PATERNIANI, S. Z.; TRINDADE, T. A. (2012). Ocupar, reivindicar, participar: sobre o repertório de ação do movimento de moradia de São Paulo. Opinião Pública. Campinas, v. 18, n. 2, pp. 399-426.

TEIXEIRA, A. C.; TRINDADE, T. A. (2018). Participação e projetos políticos: os horizontes da democracia brasileira - Entrevista com Evelina Dagnino. Ideais. Campinas, v. 9, n. 1, pp. 249-274.

TRINDADE, T. A. (2014). Ampliando o debate sobre a participação política e a construção democrática: o movimento de moradia e as ocupações de imóveis ociosos no centro da cidade de São Paulo. Tese de doutorado. Campinas, Universidade Estadual de Campinas.

VARSANYI, M. W. (2006). Interrogating "urban citizenship" vis-à-vis undocumented migration. Citizenship Studies, v. 10, n. 2, pp. 229-249.

Texto recebido em 16/jun/2019

Texto aprovado em 7/abr/2020 